\title{
Study on the Threshold Effect of China's Manufacturing Agglomeration on Energy Intensity
}

\author{
Shan $\mathrm{He}^{\mathrm{a}}$, Jing Dang \\ School of Economics and Management, Xi'an Shiyou University, Xi'an 710000, China. \\ a heshan_8211@163.com
}

\begin{abstract}
Based on the panel data of 20 industries in China's manufacturing industry from 2005 to 2015 , with the degree of industrial agglomeration as the threshold variable, the relationship between industrial agglomeration and energy intensity is studied using the threshold regression method. The empirical results show that industrial agglomeration is beneficial to reduce energy intensity within the range of lower industrial agglomeration degree. The industrial agglomeration has a negative influence on energy intensity within a high degree of agglomeration. The industrial scale and $r \& d$ investment have a positive impact on energy intensity. The decline in energy intensity has a significant inhibitory effect on the relative price of energy and the proportion of state-owned enterprises. Finally, specific Suggestions for improving energy intensity are proposed, such as reasonably guiding, controlling industrial agglomeration and reducing government intervention.
\end{abstract}

Keywords: manufacturing agglomeration; energy intensity; degree of industrial agglomeration.

\section{Introduction}

It needs to be emphasized that China's energy consumption structure belongs to the "low-quality" which energy consumption is mainly based on the coal, the oil, natural gas and renewable energy as the auxiliary pole. Then, although the energy intensity has reduced, the total energy consumption was remained growth in the past 20 years, these will largely highlight social problems, such as environmental degradation, shortage of energy and human health. Manufacturing as an important industry of energy consumption, with the process of implementation of "made in China 2025", the agglomeration of manufacturing industry in space layout of the change in situation and how to fit within the scope of the agglomeration level control to reduce energy intensity, it is a key research direction in environmental protection, reducing resource waste and maintaining economic growth in China.

\section{Literature Review}

Agglomeration refers to have the different subjects of economic activities within a particular space together, maybe the subject has the behavior of the individual worker, also maybe something else that do not have behavior ability. At present, there is no unified understanding of the concept of industrial agglomeration in academic circles, and the researchers have put forward to the corresponding connotation from their respective research perspectives. Such as Marshall (1997), the founder of New Classical School, argued that a large number of enterprises gather in a specific space, and through the division of labor to improve the production efficiency or achieve economies of scale, this process is industrial agglomeration[1]. However, modern economic researchers have given a general explanation for industrial agglomeration, which means that certain industries with certain relevance in production and operation are concentrated in certain regions (Wei Houkai 2004; Fan Jianyong et al.2014; Li Shijie et al.2014) [2-4].

There are many scholars considered the structural factors, energy prices, technological advances and regional heterogeneity, also included the nonlinearity between industrial agglomeration and influencing factors. Zhou Shengqiang (2013) by means of the panel threshold model, it is found that there was an inverted U-shaped relationship between aggregation degree and total factor productivity, and economic agglomeration was dominated by scale effect before 2003, and later the constraint of crowding effect became more and more obvious[5], Yin Xiguo (2013) studied the nonlinear relationship by used provincial panel data from 2000 to 2010 to study urban scale, transportation and 
manufacturing agglomeration, and pointed out city scale and the manufacturing industry agglomeration shows " $U$ " shaped relationship, the eastern region transportation and manufacturing agglomeration shows inverted "U" shaped relationship, the mid-west transportation will be long-term accumulation effect increasing stage[6].

As mentioned above, former literatures only considered the nonlinear relationship between the total factor productivity, urban scale, transportation with industry agglomeration, and few literatures researched the nonlinear relationship between the energy intensity and the industrial agglomeration. Based that, this paper will adopt fixed effect threshold regression model, analysis the influence of manufacturing agglomeration on non-linearity of energy intensity in the perspective of the 20 manufacturing industries, and regional heterogeneity will take into account of three major economic zones and respectively discussed.

\section{Measurement}

There are many methods to measure the level of industrial agglomeration (Wang Zilong et al.2006), this paper uses the $\mathrm{H}$ index to measure the industrial agglomeration degree, which $H H I_{\mathrm{i}}=\sum_{j=1}^{30}\left(\frac{x_{i, j}}{X_{i}}\right)^{2}$, and $x_{i, j}$ means the total industrial output value of the $i$ industrial of $j$ province; $X_{i}$ means the total industrial output value of $i$ industrial in 30 provinces which this paper study, the value of the $H H I_{i}$ is more bigger, the concentration level of the industry is more higher, and the lower the ratio of the industry, the lower the value [7].

\section{Model and Index}

\subsection{Model}

In this paper, we regard the manufacturing industry agglomeration as threshold variable using the threshold of nonlinear regression technology proposed by Hansen (1999), the research of manufacturing agglomeration effects on energy intensity in different concentration range[24]. This paper's purpose is to test the uncertain influence of manufacturing agglomeration on energy intensity. Taking the single (1) and double (2) threshold values of manufacturing agglomeration as examples, setting the following panel fixed effect threshold regression model,

$$
\begin{gathered}
E I_{i t}=\beta_{1} A G G L O_{i t} I\left(A G G L O_{i t} \leq r_{1}\right)+\beta_{2} A G G L O_{i t} I\left(A G G L O_{i t} \succ r_{1}\right)+\sum_{i=1}^{n} a_{i} X_{i t}+u_{i}+\varepsilon_{i t} \\
E I_{i t}=\beta_{1} A G G L O_{i t} I\left(A G G L O_{i t} \leq r_{1}\right)+\beta_{2} A G G L O_{i t} I\left(r_{1} \prec A G G L O_{i t} \leq r_{2}\right) \\
+\beta_{3} A G G L O_{i t} I\left(A G G L O_{i t} \succ r_{2}\right)+\sum_{i=1}^{n} a_{i} X_{i t}+u_{i}+\varepsilon_{i t}
\end{gathered}
$$

In the above formula, $E I_{i t}$ says energy intensity, $A G G L O_{i t}$ says manufacturing agglomeration degrees, $X_{i t}$ says the other factors, $\mu_{i}$ says fixed effect, $\varepsilon_{i t}$ is a random disturbance, and obeys normal distribution expectation of $0, i$ says individuals, $t$ says time.

\subsection{Variable and Data}

\subsubsection{Core Variable}

Energy intensity (EI) : energy intensity is the measure of energy consumed by per unit of GDP, which represents energy efficiency, and the unit is $t$ of standard coal/ten thousand RMB. The formula 
is $E I=\frac{e}{y}$. Among the formula, $e$ represents the total energy consumption of the industry, $y$ represents the industry sales value.

Industry agglomeration level (AGGLO) : this paper selects 20 classes in 31 class manufacturing as the research objects.

\subsubsection{Controllable Variable}

In this paper, the four variables are selected as control variables are energy relative price (EP), industry scale (IS), the proportion of state-owned enterprises (SOE) and r\&d investment (RD). Descriptive statistics are conducted for each variable before regression, and the statistical results are shown in table1.

Table 1. Variable descriptive statistics

\begin{tabular}{cccccc}
\hline Variable & Observed & Mean value & Standard deviation & Minimum value & Maximum value \\
\hline EI & 220 & 0.339 & 0.398 & 0.0238 & 2.377 \\
EP & 220 & 1.016 & 0.0569 & 0.865 & 1.196 \\
IS & 220 & 4.711 & 10.39 & 0.446 & 72.33 \\
SOE & 220 & 0.236 & 0.290 & 0.00357 & 2.602 \\
RD & 220 & 243.6 & 265.5 & 12.58 & 1612 \\
AGGLO & 220 & 0.104 & 0.0505 & 0.0595 & 0.284 \\
\hline
\end{tabular}

\section{Empirical Analysis}

\subsection{Effect Test}

This paper uses Stata14.0 to test the triple threshold effect of manufacturing agglomeration and the test results that manufacturing agglomeration effect on energy intensity is double threshold effect are reported in table2.

Table 2. The results of threshold effect test

\begin{tabular}{lccccccc}
\hline \multirow{2}{*}{ Variable } & Threshold & F value & P value & BS & \multicolumn{3}{c}{ Critical value } \\
\cline { 6 - 8 } & & & & & $10 \%$ & $5 \%$ & $1 \%$ \\
\hline \multirow{3}{*}{ AGGLO } & single & 30.43 & 0.3000 & 300 & 46.4144 & 66.7437 & 66.7437 \\
& double & $29.73 * * *$ & 0.0000 & 300 & 23.5718 & 23.6415 & 23.6415 \\
& triple & 13.26 & 0.8000 & 300 & 28.4207 & 29.095 & 29.095 \\
\hline
\end{tabular}

China's manufacturing agglomeration on energy intensity of double threshold value are 0.0716 and 0.0716 , the corresponding confidence intervals are respectively $[0.0703,0.0721]$ and $[0.0761$, 0.0770].

\subsection{Threshold Regression}

The parameter estimation is carried out based on the equation (2) which of the double threshold fixed effect threshold regression model and results are reported in table3, and, the effect of industrial agglomeration on energy intensity is not a monotonous promotion or hindrance, and its function coefficient varies fro industry agglomeration to industry agglomeration. when the industrial agglomeration degree is not more than 0.0716 , the industrial agglomeration has a negative influence on energy efficiency, and the action coefficient is -6.18633 . The reason is that industrial agglomeration brings the positive externalities are quite obvious, such as scale economy effect and knowledge spillover, which contribute to the decline of energy intensity. when the degree of industrial concentration over the threshold of 0.0716 , the effect of industrial agglomeration on energy intensity 
is enhance, and the effect coefficient is reduce to -3.03165 , the significance test is not pass. This shows that with the improvement of industrial agglomeration, the crowding effect of agglomeration starts to become prominent, while the agglomeration effect of industrial agglomeration gradually declines, but the agglomeration effect is still dominant. When the degree of industrial concentration exceeds 0.0770 , the effect coefficient of industrial agglomeration on energy intensity begins to become positive, with the gradual improvement of agglomeration, the negative influence of industrial concentration on energy intensity is increasing. Its reasons are industrial concentration exceeds the optimum size, its crowded effects dominate.

Four control variables of regression results, industry scale (IS) and r\&d investment (RD) on the energy intensity coefficient are negative, energy relative price (EP) and the proportion of state-owned enterprise (SOE) are positive. The reason is that The government's emphasis on larger enterprise will encourage them to allocate resources more rationally and the $\mathrm{r} \& \mathrm{~d}$ investment on consumption further promotes more efficient production. Finally, government intervention in energy prices is detrimental to the effective use of energy elements and the high proportion of uncompetitive SOE are would hinder energy intensity reduction.

Table 3. China's manufacturing agglomeration (AGGLO) threshold estimation results

\begin{tabular}{cccc}
\hline Explanatory variable & Coefficient & t-value & p-value \\
\hline AGGLO-0 & -6.18633 & -2.90 & 0.427 \\
AGGLO-1 & -3.03165 & -1.66 & 0.015 \\
AGGLO-2 & 1.70602 & 0.89 & 0.000 \\
EP & 0.17549 & 0.83 & 0.406 \\
IS & -0.00204 & -0.85 & 0.395 \\
SOE & 0.14985 & 2.24 & 0.026 \\
RD & -0.00037 & -4.24 & 0.000 \\
\hline
\end{tabular}

\section{Conclusions and Suggestions}

The empirical in paper results show that industrial agglomeration is not a monotonous promotion or inhibition on energy intensity in terms of samples of the whole industry. Before the optimal agglomeration degree is reached, agglomeration effect takes the dominant position and reduction of energy intensity is promoted through the common nature of labor force, technology spillover, competition effect and so on. However, after the optimal agglomeration degree is exceeded, the crowding effect is dominant and the industrial agglomeration will inhibit the decrease of energy intensity. In addition, industry scale and $r \& d$ investment have positive influence on energy intensity performance. Energy relative price and the proportion of state-owned enterprise on the energy intensity have a significant inhibition effect.

Based on the above conclusions, inspirations can be obtained:

(1) We should guide the industrial agglomeration rationally in accordance with the industry situation and avoid blind and ineffective "cluster of enterprises". At present, China's manufacturing industry is still at the low middle end of the global value chain, the market competition is not standardized which inhibits the positive externality of manufacturing agglomeration effect. Therefore, it is necessary to strictly control the competition of industry and create a positive competitive environment by protecting the innovation achievements of enterprises.

(2) We should reduce government intervention, improve the efficiency of industrial transfer and agglomeration. it is necessary to establish a perfect market economy system, reduce the government's interference in industrial development.

(3) We should raise the level of technological innovation, especially energy-saving technology, and increase the research of energy-saving equipment. Appropriately expand the scale of the 
enterprise and give full play to the scale economy effect of the enterprise. Actively promote reform of state-owned enterprises and improve the vitality of market competitiveness and innovation capabilities of state-owned and state-controlled enterprises.

\section{Acknowledgements}

Foundation item: The training project of innovation and practice ability of Xi' an Shiyou University graduate student (YCS17111021).

\section{References}

[1]. Marshall. Principles of Economics [M]. Beijing: Commercial Press. 1997.

[2]. Houkai Wei. Characteristics, problems and countermeasures of industrial agglomeration in China [J]. Economic Dynamics. 2004 (9): 58-61.

[3]. Jianyong Fan, Meng Feng, Fangwen Li. Industrial agglomeration and enterprise total factor productivity [J]. World Economy, 2014 (5): 51-73.

[4]. Mingchen Xu, Anjian Wang, Qishen Chen, et al. Analysis of China's energy consumption intensity trend [J]. Acta Geoscientia Sinica, 2010, 10 (31): 720-726.

[5]. Shengqiang Zhou and Weiping Zhu. Can industrial agglomeration bring economic efficiency: scale effect and crowding effect [J]. Industrial Economy Research, 2013 (3): 12-22.

[6]. Xiguo Yin, Peisen Liu. Study on the influencing factors of manufacturing agglomeration in China--on the non-linear relationship between urban scale, transportation and manufacturing agglomeration [J]. Economic Geography, 2013, 33 (12): 97-103.

[7]. Zilong Wang, Qingmei Tan, Xiaodi Xu. Empirical study on industrial agglomeration level measurement [J]. China Soft Science, 2006 (3): 109-116. 